\title{
AVALIAÇÃO DA BIOMASSA DE FUNGOS AMAZÔNICOS COMO FONTE DE LIPASES PARA BIOCATÁLISE
}

\author{
Israel P. Romano ${ }^{\mathrm{a}, *, \odot}$, Vanderlei S. dos Santos ${ }^{\mathrm{b}}$, Ana Carolina de Lima Paes Louzada ${ }^{\mathrm{c}}$, Raimundo C. Pereira Junior ${ }^{\mathrm{d}}$, Edson \\ J. do Carmo ${ }^{\mathrm{e}}$, Adolfo José da Mota ${ }^{\mathrm{e}}$, Hiléia dos S. Barroso ${ }^{\mathrm{f}}$, Ivaldo Itabaiana Junior ${ }^{\mathrm{g}}$, José Odair Pereira ${ }^{\mathrm{e}}$, Spartaco Astolfi \\ Filho $^{\mathrm{e}}$ e Sandra Patrícia Zanotto ${ }^{\mathrm{b}}$ \\ aDepartamento de Pesquisa, Ensino e Pós-graduação - Instituto Federal de Educação, Ciência e Tecnologia, Parintins - AM, Brasil \\ ${ }^{\mathrm{b} C e n t r a l ~ d e ~ A n a ́ l i s e ~ Q u i ́ m i c a, ~ C e n t r o ~ d e ~ B i o t e c n o l o g i a ~ d a ~ A m a z o ̂ n i a, ~ M a n a u s ~-~ A M, ~ B r a s i l ~}$ \\ ${ }^{\mathrm{c}}$ Escola Superior Batista do Amazonas, Manaus - AM, Brasil \\ ${ }^{d}$ Universidade do Estado do Amazonas, Campus Tefé, Tefé - AM, Brasil \\ 'Instituto de Ciencias Biológicas, Universidade Federal do Amazonas, Manaus - AM, Brasil \\ fDepartamento de Pesquisa, Ensino e Pós-graduação, Instituto Federal de Educação, Ciência e Tecnologia, Manaus - AM, Brasil \\ ${ }^{\mathrm{g}}$ Escola de Química, Universidade Federal do Rio de Janeiro, Rio de Janeiro - RJ, Brasil
}

Recebido em 25/06/2019; aceito em 06/11/2019; publicado na web em 03/02/2020

\begin{abstract}
EVALUATION OF AMAZONIAN FUNGI BIOMASS AS A SOURCE OF LIPASES FOR BIOCATALYSIS. We evaluated the biomass of twenty Amazonian fungal isolates as a potential source of mycelium-bound lipases with hydrolytic, synthetic or enantioselective activity for biocatalysis application. We compared the hydrolytic activity of three biomass treatments (delipidated, non-delipidated and cultivated in medium without inducer). Delipidated biomass showed better results in the hydrolysis of $p$-nitrophenyl palmitate compared to the other two treatments for fifteen isolates. Delipidated biomass of six Aspergillus strains and UEA_115 strain showed a high synthesis activity of ethyl palmitate by transesterification in organic medium. Results were confirmed by spectrophotometry $(410 \mathrm{~nm})$ and gas chromatography. In this reaction, the isolate DPUA_1539 A. flavo-furcatis reached a maximum value of $668.5 \pm 23.5 \mathrm{mU} \mathrm{g}^{-1}$. Enantioselective activity assays indicated that biomass-bound lipases from UEA_115 isolate $\left(\mathrm{E}=3.58 ; \mathrm{e}_{\mathrm{s}}=7 \pm 0\right)$ and in particular from the DPUA_1539 A. flavo-furcatis isolate $\left(\mathrm{E}=24.15\right.$ ee $\left._{\mathrm{s}}=91 \pm 1\right)$ have the ability to discriminate enantiomers of the drug ibuprofen by ester synthesis, preferably with $(R)$-enantiomer. These results encourage further investigations of these fungi as potential lipase suppliers for biocatalytic processes such as biodiesel production and enantiopure drugs.
\end{abstract}

Keywords: lipase; biocatalysis; biomass; enantioselectivity; transesterification; amazonian fungi.

\section{INTRODUÇÃO}

A biocatálise tem se tornado uma ferramenta cada vez mais importante da biotecnologia. Esse campo de pesquisa, em alguns casos, possibilitou reações que não são facilmente conduzidas pela química orgânica clássica e, em outros casos, promoveu reações que podem substituir etapas químicas de alto custo energético e/ou ambiental. Cerca de dois terços da pesquisa em biotransformação envolvem hidrolases, com especial destaque para as lipases. ${ }^{1,2}$

Lipases são triacilglicerol éster hidrolases (EC 3.1.1.3) cuja capacidade de realizar tanto reações hidrolíticas como de síntese - conforme o meio reacional seja aquoso ou não-aquoso - tem sido extensivamente estudadas e empregadas na indústria já por várias décadas. ${ }^{3-5}$ Detergentes, desengordurantes e outros agentes de limpeza são algumas das aplicações consolidadas da atividade hidrolítica destas enzimas. A atividade sintética de lipase, por sua vez, tem aplicações de grande interesse econômico e alto impacto na qualidade de vida, como a produção de cosméticos, de alimentos funcionais enriquecidos com ácidos graxos poli-insaturados e de biodiesel a partir de resíduos oleaginosos. ${ }^{5-7} \mathrm{O}$ biodiesel é um combustível líquido composto por monoalquil ésteres e pode ser obtido por transesterificação biocatalisada. Em ambientes aquorrestritos, lipases podem sintetizar monoalquil ésteres a partir da transesterificação de triacilgliceróis, tornando o processo mais atrativo para o uso com matérias-primas de baixo valor agregado. ${ }^{6,89}$

Lipases com atividade enantiosseletiva são de grande interesse para resolução de racematos e obtenção de blocos quirais para síntese

*e-mail: israel.paes@ifam.edu.br química. O mercado para compostos enantiopuros está em crescimento, tornando a obtenção destas moléculas um atrativo campo de pesquisa. ${ }^{10,11}$ Por exemplo, o ibuprofeno - um dos medicamentos mais consumidos no mundo - é uma molécula quiral cuja atividade farmacológica reside majoritariamente no $(S)$-enantiômero, o qual é 160 vezes mais ativo que o correspondente $(R)$-enantiômero. Assim, a obtenção do $(S)$-enantiômero opticamente puro é de grande relevância. ${ }^{11-13}$

As numerosas aplicações industriais das lipases têm estimulado o interesse no isolamento de novas lipases a partir de novas fontes. O desenvolvimento de metodologias e estratégias para seleção de lipases com atividade sintética e enantiosseletiva continua sendo um tópico relevante. ${ }^{14-16}$ Rapidez, confiabilidade e baixo custo são as principais características almejadas, mas é difícil combiná-las numa única metodologia.

As lipases microbianas têm sido mais amplamente empregadas em processos industriais do que as derivadas de plantas e animais devido à sua maior termoestabilidade, tolerância a variações de $\mathrm{pH}$ e estabilidade em solventes orgânicos. Além disso, elas têm maiores rendimentos de produção, facilidade de manipulação genética e crescimento rápido em meios de baixo custo. Entre as fontes microbianas, os fungos filamentosos se destacam como fornecedores de lipases para uma ampla - e sempre crescente - gama de aplicações. ${ }^{17,18}$

A imobilização enzimática possibilita a manutenção da atividade catalítica por mais tempo, além de facilitar a recuperação e reutilização do biocatalisador. Inúmeras estratégias têm sido propostas para a imobilização de enzimas extracelulares. Por outro lado, a biomassa fúngica, também chamada micélio, possui toda uma maquinaria enzimática própria. As enzimas ligadas ao micélio 
podem ser consideradas enzimas naturalmente imobilizadas, e têm uma óbvia atração de custo em comparação com o uso de enzimas livres ou solúveis em biotransformações. Assim, a biomassa fúngica pode ser usada como uma fonte direta da enzima, eliminando a necessidade de isolamento, procedimentos de extração, purificação e imobilização externa. ${ }^{1,19,20}$

Espécies da biodiversidade de fungos da Amazônia, potencial fonte de enzimas para diversos campos da biotecnologia, ainda são pouco conhecidas, embora os estudos acerca da biocatálise tenham avançado mundialmente. Trabalhos de screening da biodiversidade em busca de novos biocatalisadores contribuem para o conhecimento e valorização dos recursos naturais amazônicos, fortalecendo as iniciativas para a conservação destes recursos. ${ }^{20}$

Neste estudo, foi investigado o potencial da biomassa de seis linhagens de Aspergillus e de quatorze linhagens fúngicas não-identificadas, todas coletadas na região amazônica, como fonte de lipases ligada ao micélio para aplicações em biocatálise, tanto em meio aquoso (atividade hidrolítica) como em meio orgânico (atividade sintética e enantiosseletiva). Comparou-se o efeito de três tratamentos da biomassa sobre a atividade hidrolítica. A atividade sintética foi avaliada por um ensaio de transesterificação e quantificada por duas metodologias diferentes. A capacidade enantiosseletiva das lipases foi avaliada por meio da resolução do fármaco $(R, S)$-ibuprofeno.

\section{PARTE EXPERIMENTAL}

\section{Reagentes}

Foram utilizados neste estudo maltose da marca Vetec e peptona da marca Difco. Fosfato de potássio bibásico, fosfato de sódio bibásico e sulfato de magnésio, todos de grau PA, foram comprados da fornecedora Nuclear. O óleo de oliva comercial extravirgem marca Gallo foi adquirido no comércio local. Os solventes de grau PA hexano, clorofórmio, éter, ácido acético glacial, acetona e álcool butílico foram adquiridos da empresa CRQ. Triton-X PA foi comprado da Neon e a goma arábica da empresa Synth. Os padrões de alta pureza grau CG (> 98\%) palmitato de p-nitrofenila, p-nitrofenol, $(R, S)$-ibuprofeno, $(S)$-ibuprofeno, palmitato de etila e palmitato de metila, bem como os solventes grau HPLC heptano, hexano, isooctano e etanol, além do derivatizador $N$-metil- $N$-trimetilsilil-trifluoroacetamida (MSTFA) e da peneira molecular de 4 Angström foram comprados da Sigma-Aldrich. Os solventes grau HPLC 1-propanol, 2-propanol, bem como o ácido cítrico monoidratado PA foram adquiridos da J. Baker. Ácido acético grau HPLC foi comprado da Merck. O fármaco ibuprofeno racêmico marca MOTRIN 600 mg (Pfizer) foi comprado numa farmácia local.

\section{Microrganismos e condições de cultivo}

\section{Procedência dos isolados}

Seis linhagens certificadas de cinco espécies do gênero Aspergillus foram gentilmente cedidas pela Coleção do Departamento de Parasitologia da Universidade Federal do Amazonas (DPUA-UFAM), na forma de culturas esporuladas: A. niger DPUA_398, A. niger DPUA_399, A. japonicus DPUA_613, A. foetidus DPUA_1245, A. awamorii DPUA_1473 e A. flavo-furcatis DPUA_1539. Quatorze linhagens não identificadas foram gentilmente cedidas por colegas pesquisadores do Programa de Pós-Graduação Mestrado em Biotecnologia e Recursos Naturais da Universidade do Estado do Amazonas (MBT-UEA) na forma de micélios vegetativos conservados em água destilada estéril. Estas linhagens foram isoladas a partir dos corpos de frutificação de macrofungos coletados nos fragmentos florestais de instituições de pesquisa da região, e incluídas no presente trabalho por terem apresentado atividade de lipase em testes preliminares com os substratos tributirina ou óleo de oliva. São referenciados neste artigo pelo prefixo "UEA_" seguido de um código individual. Uma linhagem que apresentou significativa atividade sintética e enantiosseletiva foi identificada em nível de espécie através de técnicas moleculares. ${ }^{21}$

\section{Fermentação submersa}

Todas as vinte linhagens foram cultivadas em meio líquido preparado segundo Sun et al..$^{22}(\%, \mathrm{p} / \mathrm{v})$ : maltose 0,5 ; peptona 4,$0 ; \mathrm{K}_{2} \mathrm{HPO}_{4}$ 0,$3 ; \mathrm{MgSO}_{4} 0,05$; óleo de oliva comercial 2.4. O pH foi ajustado para 5,5. A fermentação submersa foi conduzida em frascos de erlenmeyer de $250 \mathrm{~mL}$ contendo $20 \mathrm{~mL}$ do meio. No cultivo das linhagens das espécies de Aspergillus, os frascos foram inoculados com um volume de suspensão de esporos para obter a concentração de 1 x $10^{6}$ esporos/L. A quantidade de esporos nas suspensões foi determinada por contagem em câmara de Neubauer. Os frascos inoculados foram incubados em agitador orbital a $200 \mathrm{rpm}, 30{ }^{\circ} \mathrm{C}$, por 5 dias. Para as demais linhagens não esporuladas, utilizou-se como inóculo três discos de micélio de aproximadamente $10 \mathrm{~mm}$ de diâmetro em cada frasco. Visto que testes preliminares indicaram que a massa micelial das linhagens não esporuladas crescia melhor em cultivo estático, elas foram incubadas em BOD sem agitação à $28^{\circ} \mathrm{C}$ por 7 dias.

\section{Fermentação em meio sem indutor}

Com o propósito de confirmar a eficiência do óleo de oliva comercial como indutor da produção lipase, bem como verificar a presença de lipases constitutivas na biomassa, todos os isolados foram submetidos também à fermentação submersa em meio Sun sem adição do óleo de oliva, nas mesmas condições descritas acima.

\section{Preparação do micélio para uso como biocatalisador}

\section{Coleta e dessecagem}

Após o período de incubação, o micélio crescido nos frascos foi coletado do meio de cultivo por filtração simples sobre gazes esterilizadas, realizada em capela de fluxo laminar. $\mathrm{O}$ caldo de cultivo foi armazenado sob refrigeração para uso posterior. Em seguida à filtração simples, a biomassa micelial de cada isolado foi lavada e filtrada à vácuo com $100 \mathrm{~mL}$ de água destilada estéril e $100 \mathrm{~mL}$ de acetona, respectivamente. O micélio lavado e filtrado foi dessecado sob vácuo até peso constante ${ }^{23}$ - em média por $96 \mathrm{~h}$.

\section{Delipidação, trituração e peneiramento}

A remoção dos lipídios impregnados nos micélios que cresceram em meio com óleo de oliva foi realizada utilizando-se $10 \mathrm{~mL}$ de uma solução clorofórmio: butanol (9:1). O sistema contendo micélio e solução de clorofórmio:butanol foi colocado sob agitação $(200 \mathrm{rpm}$, $40{ }^{\circ} \mathrm{C}, 15 \mathrm{~min}$ ). Em seguida, o micélio foi coletado e novamente lavado sob agitação com mais $10 \mathrm{~mL}$ da mesma solução. Retirou-se uma fração da solução utilizada na segunda lavagem e verificou-se a remoção dos lipídios por cromatografia de camada delgada, pela comparação com soluções do óleo de oliva comercial e de ácido oleico PA. O eluente utilizado foi hexano: éter: ácido acético (7:3:0,1), empregando-se iodo como revelador. Quando necessário, o procedimento foi repetido. ${ }^{24} \mathrm{O}$ micélio delipidado foi dessecado sob vácuo por $24 \mathrm{~h}$ e depois triturado a pó e peneirado com uma peneira simples de cozinha, resultando numa preparação bruta de lipases ligadas ao micélio para utilização como biocatalisador nas reações.

\section{Biomassa não-delipidada e biomassa crescida em meio sem indutor}

Visando avaliar o efeito da delipidação sobre a atividade hidrolítica das lipases, uma fração da biomassa de todas as linhagens 
cultivadas em meio com óleo de oliva foi dessecada, triturada e peneirada sem ser submetida ao processo de delipidação. A biomassa obtida a partir do crescimento das linhagens em meio sem óleo de oliva foi tratada do mesmo modo que a biomassa não-delipidada.

\section{Avaliação da atividade hidrolítica}

\section{Ensaio enzimático}

O ensaio de hidrólise do pNPP (palmitato de p-nitrofenila), que libera p-nitrofenol (pNP) detectado por espectrofotometria, foi usado para avaliar a atividade hidrolítica das lipases ligadas ao micélio. Dez $\mathrm{mL}$ de $\mathrm{pNPP}$ em isopropanol $\left(3,2 \mathrm{mg} \mathrm{mL}^{-1}\right)$ foram emulsificados com $90 \mathrm{~mL}$ de uma solução aquosa de goma arábica $0,1 \%$ e Triton-X-100 $0,4 \%$. No ensaio enzimático foram utilizados $900 \mu \mathrm{L}$ do substrato emulsificado e 05 miligramas de micélio delipidado e triturado suspensos em $100 \mu \mathrm{L}$ de tampão citrato-fosfato $\left(0,5 \mathrm{~mol} \mathrm{~L}^{-1} ; \mathrm{pH} 5\right)$, resultando numa concentração final de $0.85 \mathrm{mmol} \mathrm{L}^{-1}$ de pNPP. A reação foi realizada em microtubos de $2 \mathrm{~mL}$ incubados em agitador orbital $\left(40{ }^{\circ} \mathrm{C}, 150 \mathrm{rpm}\right)$, por dois minutos. Imediatamente após este tempo, o sistema reacional foi centrifugado (14.000 g, $2 \mathrm{~min}) \mathrm{e}$ coletou-se o sobrenadante. ${ }^{25}$

O pNP liberado foi detectado a $410 \mathrm{~nm}$ e quantificado a partir de uma curva padrão $\left(\mathrm{R}^{2}=0,9988\right)$ feita com concentrações conhecidas deste composto. Os brancos foram obtidos pela leitura do sistema reacional sem micélio. Uma unidade de atividade enzimática foi definida como a quantidade de enzima que liberou 1 micromol de pNP por minuto, nas condições deste ensaio. A atividade específica foi expressa em miliunidades por grama de biomassa seca $\left(\mathrm{mU} \mathrm{g}^{-1}\right)$.

Foram também realizados ensaios utilizando a biomassa não-delipidada e a biomassa cultivada em meio sem indutor de todos os isolados fúngicos, nas mesmas condições descritas acima.

\section{Testes estatísticos}

O teste ANOVA de um fator, com nível de significância de 5\% e pós-teste de agrupamento de Tukey, assumindo-se a igualdade das variâncias, foi aplicado para verificar a igualdade das médias da atividade hidrolítica. Inicialmente, o teste foi aplicado para cada isolado fúngico em separado, a fim de avaliar a significância estatística da diferença dos resultados obtidos com os três tratamentos aplicados ao micélio (delipidado, não-delipidado e crescido em meio sem indutor). A seguir, as médias de todos os isolados fúngicos obtidas com micélio delipidado foram testadas. Os resultados são apresentados como a média de três réplicas e seu desvio-padrão. O software estatístico empregado foi o Minitab 18 para Windows.

\section{Avaliação da atividade sintética}

\section{Ensaio enzimático de transesterificação em meio orgânico}

Foi utilizado o ensaio de transesterificação entre pNPP e etanol, produzindo $\mathrm{pNP}$ e palmitato de etila (PEt). ${ }^{26} \mathrm{Em}$ microtubos de $2 \mathrm{~mL}$ contendo $50 \mathrm{mg}$ de micélio triturado foi aliquotado $1 \mathrm{~mL}$ de uma solução $10 \mathrm{mmol} \mathrm{L}^{-1}$ de pNPP em n-heptano. A reação foi iniciada com a adição de $60 \mu \mathrm{L}$ de etanol $1 \mathrm{~mol} \mathrm{~L}^{-1}$. Os microtubos foram incubados em agitador orbital termostatizado, a $40{ }^{\circ} \mathrm{C}, 200 \mathrm{rpm}$, durante $30 \mathrm{~min}$. Devido a maior quantidade de micélio necessária para a sua realização, os ensaios foram conduzidos em duplicata.

Após os 30 minutos de reação, o conteúdo de cada microtubo foi coletado com uma seringa de vidro e filtrado (PTFE hidrofóbico, $13 \mathrm{~mm}$ de diâmetro, poro de $0,45 \mu \mathrm{m}$ ), para remoção do micélio e interrupção da biocatálise. O sistema reacional filtrado foi utilizado na determinação da atividade sintética de lipase por duas metodologias diferentes, descritas a seguir.
Determinação por espectrofotometria da atividade sintética pela detecção do pNP liberado

Imediatamente após a filtração, $25 \mu \mathrm{L}$ do filtrado foram coletados e misturados com $1 \mathrm{~mL}$ de uma solução de $\mathrm{NaOH} 0,1 \mathrm{~mol} \mathrm{~L}^{-1}$, possibilitando que o pNP eventualmente liberado na reação fosse extraído da fase orgânica para a fase aquosa alcalina. A seguir, $200 \mu \mathrm{L}$ de cada fase aquosa alcalina foram transferidos para os poços de uma microplaca de titulação (96 poços). O pNP foi detectado a $410 \mathrm{~nm}$ utilizando um espectrofotômetro de UV-visível com leitor de microplacas (modo PathCheck) da SpectraMax 384 Molecular Devices. Os brancos foram obtidos pela leitura do sistema reacional sem micélio. A liberação de pNP foi calculada a partir de uma curva padrão $\left(R^{2}=0,9948\right)$ feita com concentrações conhecidas deste composto.

\section{Determinação da atividade sintética pela detecção da formação de} PEt por CG-DIC

Quarenta microlitros do meio reacional filtrado foram misturados com $20 \mu \mathrm{L}$ de MSTFA em vials de vidro de $2 \mathrm{~mL}$, para derivatização dos ácidos graxos residuais. Após 15 minutos, adicionou-se $900 \mu \mathrm{L}$ de heptano e $40 \mu \mathrm{L}$ do padrão interno palmitato de metila $(40 \mu \mathrm{L}$ $\mathrm{mL}^{-1}$ ), para completar o volume de $1 \mathrm{~mL}$.

As análises cromatográficas foram realizadas no CG-DIC modelo QP2010, fabricante Shimadzu, equipado com autoinjetor modelo AOC 20i, do mesmo fabricante. O equipamento foi programado para injetar $1 \mu \mathrm{L}$ de cada amostra. O CG-DIC foi configurado inicialmente para injeção em modo split a 10 e temperatura do injetor a $250{ }^{\circ} \mathrm{C}$. Foi utilizado hélio como gás de arraste. O fluxo total foi ajustado $14,0 \mathrm{~mL} \mathrm{~min}^{-1}$, e o fluxo da coluna $1.00 \mathrm{~mL} \mathrm{~min}^{-1}$. A coluna capilar utilizada foi de sílica fundida, modelo Restek RTX-5 de $28 \mathrm{~m}$ x 0,25 mm de diâmetro interno e $0,25 \mu \mathrm{m}$ de filme interno de difenil dimetil polisiloxano (Agilent). A rampa de aquecimento da coluna iniciou em $180^{\circ} \mathrm{C}$, por 3 minutos. Depois a temperatura foi elevada a taxa de $6^{\circ} \mathrm{C} \min ^{-1}$ até $280^{\circ} \mathrm{C}$, finalizando o tempo de corrida em 19,67 minutos. O detector DIC foi configurado a temperatura de $300{ }^{\circ} \mathrm{C}$ com make-up de gás hélio em fluxo de $30,0 \mathrm{~mL} \mathrm{~min}^{-1}$, o fluxo de gás de hidrogênio a $40 \mathrm{~mL} \mathrm{~min}^{-1}$, fluxo de ar sintético a

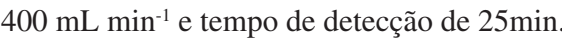

A identificação dos picos cromatográficos foi feita pela comparação com os tempos de retenção dos picos de padrões de alta pureza, injetados nas mesmas condições. A quantidade de PEt sintetizada foi calculada com base nas áreas do picos cromatográficos, utilizando-se uma curva padrão $\left(\mathrm{R}^{2}=0,9995\right)$, obtida pela aplicação da formula:

$$
F R=\frac{A \cdot P \cdot I}{A \cdot P \cdot A}
$$

em que $\mathrm{FR}=$ fator de resposta; A.P.I. = área do pico padrão interno e A.P.A = área do pico do padrão analítico, para concentrações conhecidas do padrão interno e do analito

\section{Avaliação da atividade enantiosseletiva}

A capacidade das lipases ligadas ao micélio apresentarem enantiopreferência foi avaliada no ensaio de esterificação do ibuprofeno racêmico presente no fármaco Motrin. $\mathrm{O}$ solvente isooctano foi previamente seco com peneira molecular $0,2 \%(\mathrm{p} / \mathrm{v})$. Na preparação deste ensaio os comprimidos do fármaco foram triturados e pesados para corresponder à concentração desejada, e adicionados ao solvente. A mistura foi solubilizada em agitador orbital $\left(200 \mathrm{rpm}, 40^{\circ} \mathrm{C}\right)$ por 30 minutos. $\mathrm{O}$ excipiente insolúvel foi removido por filtração à vacuo com membrana filtrante (PTFE hidrofóbico, $47 \mathrm{~mm}$ de diâmetro, poro de $0,45 \mu \mathrm{m})$. Um mL da solução filtrada foi lido a $254 \mathrm{~nm}$ 
numa cubeta de quartzo e a concentração do analito foi determinada com o auxilio de uma curva de calibração $\left(\mathrm{R}^{2}=0,9987\right)$ feita a partir de concentrações conhecidas de um padrão de alta pureza. Quando necessario, adicionou-se isooctano seco ou $(R, S)$-ibuprofeno puro. $\mathrm{O}$ meio reacional padrão foi composto por $10 \mathrm{~mL}$ de solução de ibuprofeno racêmico $(60 \mathrm{mM})$ e 1-propanol $\left(150 \mathrm{mmol} \mathrm{L}^{-1}\right)$ em isooctano. A reação foi iniciada pela adição de $0,3 \mathrm{~g}$ de micélio triturado e realizada em erlenmeyers de $100 \mathrm{~mL}$ selados com papel alumínio e filme de pvc. O sistema reacional foi colocado sob agitação $\left(200 \mathrm{rpm}, 40^{\circ} \mathrm{C}\right)$. Experimentos sem adição de micélio foram realizados para avaliação da porcentagem de esterificação espontânea do sistema. Aliquotas de $100 \mu \mathrm{L}$ foram coletadas em diferentes tempos e diluídas em $1,4 \mathrm{~mL}$ de isooctano seco para análise por cromatografia liquida de alta eficiênica em coluna quiral. ${ }^{27}$ Os ensaios foram realizado em duplicata.

O equipamento empregado na análise foi o UFLC Shimadzu modelo LC-20AD, acomplado com detector UV-Vis modelo SPD- M20A e auto injetor SIL-20 AHT. A coluna quiral foi a Astec Celulose DMP 5UM ( $25 \mathrm{~cm} \mathrm{x} \mathrm{4,6} \mathrm{mm).} \mathrm{A} \mathrm{fase} \mathrm{móvel} \mathrm{usada} \mathrm{foi} \mathrm{hexano/isopropanol/}$ ácido acético na proporção de 98/2/0,5 v/v com fluxo de $0,4 \mathrm{~mL} \mathrm{~min}{ }^{-1}$ em condição isocrática. O comprimento de onda monitorado foi de $254 \mathrm{~nm}$. O tempo total de corrida para cada amostra foi de $25 \mathrm{~min}$. A identificação dos picos correpondentes aos enantiômeros $(R)$ e $(S)$ do ibuprofeno foi realizada por comparação do tempo de retenção da amostra com os de padrões de alta pureza injetados nas mesmas condições. A quantidade de cada enantiômero foi calculada a partir de uma curva padrão $\left(\mathrm{R}^{2}=0,9997\right.$ para ambos) das áreas dos picos detectados em concentrações conhecidas. A capacidade enantiosseletiva das lipases foi determinanda levando-se em conta o valor de conversão $(c)$ conforme cálculos propostos nas literatura. ${ }^{28,29}$

$$
c=1-\frac{S+R}{S_{0}+R_{0}}
$$

em que $\mathrm{S}=$ concentração final do enantiômero $(S) ; \mathrm{R}=$ concentração final do enantiômero $(R) ; \mathrm{S}_{0}=$ concentração inicial do enantiômero $S ; \mathrm{R}_{0}=$ concentração inicial do enantiômero $R$.

Os valores de excesso enantiomérico do substrato $\left(e e_{s}\right)$ e razão enantiomérica $(E)$ segundo os calculos propostos por Faber: ${ }^{30}$

$$
e e_{s}=\frac{S-R}{S+R}
$$

em que $S$ = concentração final do enantiômero $(S)$ e $R=$ concentração final do enantiômero $(R)$.

$$
E=\frac{\ln \left[(1-c)\left(1-e e_{s}\right)\right]}{\ln \left[(1-c)\left(1+e e_{s}\right)\right]}
$$

em que $c=$ conversão e $e e_{s}=$ excesso enantiomerico do substrato.

\section{Identificação molecular}

A extração do DNA total foi realizada a partir de $1 \mathrm{mg}$ de micélio fresco com o kit Plant/Fungi DNA Isolation (Norgen Biotek Corp). A região do DNA ribossômico de interesse foi amplificada por PCR com os primers ITS1 e UniR. ${ }^{31}$ A PCR foi realizada com o kit GoTaq Flexi (Promega) seguindo as recomendações do fabricante. O produto da PCR foi purificado com o kit Purelink PCR purification (Invitrogen by Thermo) e quantificado em um fluorímetro Qubit 2.0 com o kit dsDNA (Invitrogen by Thermo). Dez nanogramas dos amplicons puros alimentaram a reação de sequenciamento com o kit BigDye Terminator, v.3.1, usando os primers já citados. As sequências foram determinadas em um analisador genético ABI3500 (Applied Biosystems by Thermo), editadas no programa SeqMan Pro e comparadas com a base de dados do GenBank usando a ferramenta BlastN. ${ }^{32}$

\section{RESULTADOS E DISCUSSÃO}

\section{Avaliação da atividade hidrolítica}

A Figura 1 mostra os resultados das atividades hidrolíticas avaliadas por testes ANOVA para igualdade e de Tukey para agrupamento das médias dos três tratamentos da biomassa.

\section{Comparação dos tratamentos}

Em todos os vinte isolados fúngicos testados, a média de pelo menos um dos três tratamentos foi avaliada como estatisticamente diferente. Para quinze isolados, a biomassa delipidada foi o tratamento que obteve as médias mais altas de atividade enzimática, e onze destas médias mais altas foram avaliadas como tendo significância estatística. Estes dados confirmam a estabilidade das lipases ligadas ao micélio como enzimas naturalmente imobilizadas, capazes de suportar um tratamento agressivo (a lavagem com solução clorofórmio:butanol) sem perda da atividade. De fato, a delipidação da biomassa, via de regra, teve o efeito de aumentar a atividade hidrolítica. Uma possível explicação para esse efeito seria o aumento da superficie de contato das lipases com o substrato, propiciada pela remoção dos lipídios impregnados.

Para quatro linhagens fúngicas, o tratamento que obteve as maiores médias foi a biomassa não-delipidada. Verifica-se desse modo que dezenove dos vinte isolados apresentaram maior atividade hidrolítica com a biomassa cultivada em presença do óleo de oliva. Esses resultados estão de acordo com a literatura a respeito da eficiência do óleo de oliva como indutor da produção de lipase em microrganismos - e justificam o uso do azeite comercial como substituto de baixo custo ao óleo de alta pureza.

Por outro lado, todas as linhagens apresentaram alguma atividade hidrolítica na biomassa crescida em meio sem indutor, mesmo que em quantidade comparativamente baixa, como no caso do isolado UEA_361a (aproximadamente $260 \mathrm{mU} \mathrm{g}^{-1}$ ). Esses resultados indicam a presença de lipase constitutiva em todos os micélios. $\mathrm{O}$ isolado UEA_025 foi o que exibiu a mais alta atividade de lipase constitutiva (17.250 $\left.\mathrm{mU} \mathrm{g}^{-1}\right)$, sendo esse o único fungo no qual o tratamento sem indutor exibiu maior atividade do que os outros dois tratamentos, e com diferença estatisticamente significativa.

\section{Comparação dos resultados obtidos com a biomassa delipidada}

Visto que a maioria dos isolados apresentou os melhores resultados com a biomassa delipidada, a média obtida com este tratamento foi escolhida para comparação dos isolados entre si. A Figura 2 mostra os resultados dos testes ANOVA para a igualdade e de Tukey para o agrupamento destas médias. Na figura, letras iguais entre as médias representam valores iguais para um nível de significância de 5\%.

Os isolados fúngicos prefixo UEA_F07, 361, F06, F04 E 364 obtiveram, respectivamente, as médias mais altas de atividade hidrolítica, variando de $31.214 \pm 4.935$ a $22.671 \pm 4.589 \mathrm{mU} \mathrm{g}^{-1}$. Entrentanto, a diferença entre as médias destes isolados não foi avaliada como estatisticamente significativa. Por outro lado, a menor atividade hidrolítica dentre os vinte isolados foi também de uma linhagem da UEA, a 207, que alcançou 7.927 $\pm 290 \mathrm{mU} \mathrm{g}^{-1}$.

Dentre os fungos do genero Aspergillus testados, a maior média foi obtida com a linhagem DPUA_398 A. niger $\left(16.366 \pm 550,76 \mathrm{mU} \mathrm{g}^{-1}\right)$ e a menor, com a linhagem DPUA_1539 A. flavo-furcartis $\left(10.155 \pm 245 \mathrm{mU} \mathrm{g}^{-1}\right)$. 


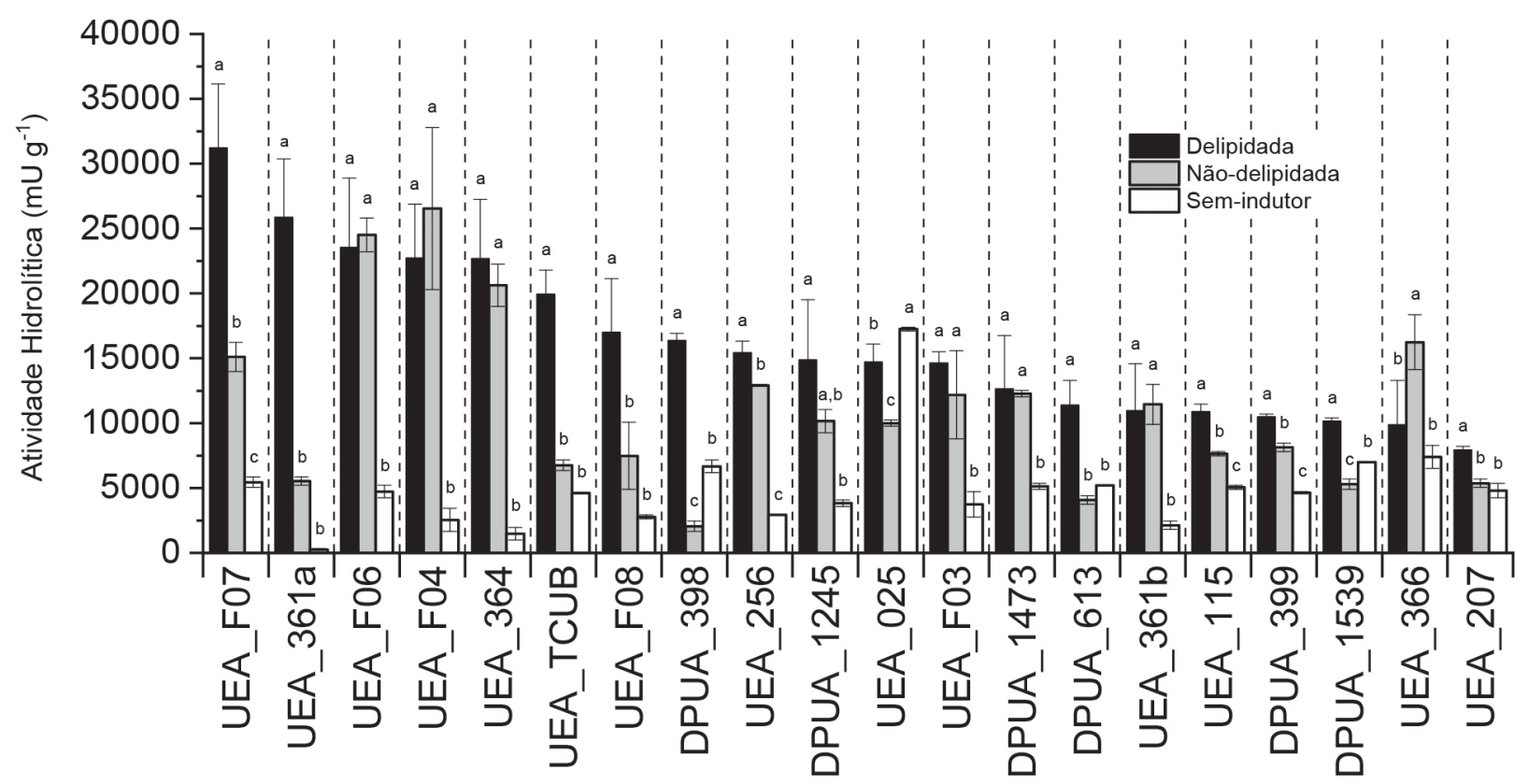

Isolados fúngicos

Figura 1. Testes ANOVA de igualdade entre as médias e pós-teste de Tukey da atividade hidrolítica das biomassas delipidada, não-delipidada e crescida em meio sem indutor, de vinte isolados fúngicos. Os testes foram aplicados para as médias dos tratamentos da biomassa de cada isolado fúngico separadamente. Letras iguais entre as médias dos tratamentos de um mesmo isolado representam valores iguais para um nível de significância de $5 \%$. Letras iguais entre médias dos tratamentos de isolados diferentes não implicam em valores estatisticamente iguais

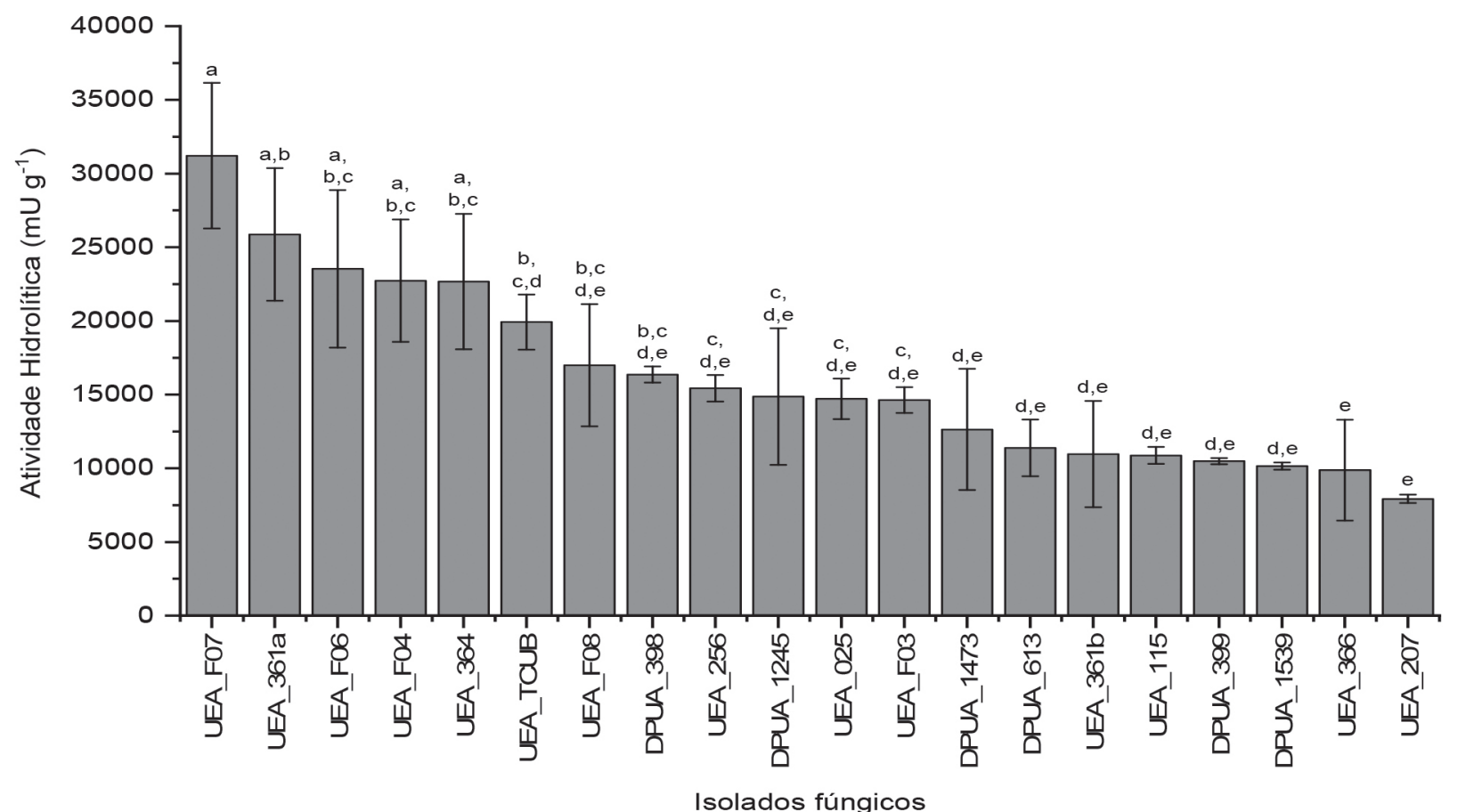

Figura 2. Testes de igualdade entre as médias da atividade hidrolítica da biomassas delipidada de vinte isolado fúngicos. Letras iguais entre as médias representam valores iguais para um nível de significância de 5\%

Na literatura, entre os estudos que avaliaram a atividade de lipase ligada ao micélio pelo ensaio de hidrólise de pNPP, existem significativas variações no procedimento de ensaio - por exemplo, nas proporções entre pNPP e emulsificante e na composição do tampão utilizado. Há variações também nas formulações dos meios de cultivo da biomassa, bem como nos tratamentos aos quais a biomassa foi submetida (lavagem, filtração, dessecagem, liofilização, delipidação etc). Essas diferenças na metodologia sem dúvida relativizam qualquer comparação dos valores de atividade hidrolítica entre os trabalhos publicados. Ainda assim, tal comparação pode fornecer indícios sobre quais linhagens de microrganismos - e quais condições de cultivo/ tratamento da biomassa - são provavelmente mais promissoras na triagem de lipases com elevada capacidade de hidrólise.

Um cotejo dos resultados apresentados nesta seção com os de outros estudos que também avaliaram lipases ligadas ao micélio pela hidrólise de pNPP mostrou que, na maioria dos casos, a atividade 
hidrolítica das linhagens amazônicas testadas neste trabalho foi mais alta. Regner et al.,$^{33}$ trabalhando com A. niger (linhagem MYA 135) e testando diversas formulações de meio preparadas a partir de matérias primas e resíduos agro-industriais, obtiveram aproximadamente $850 \mathrm{mU} \mathrm{g}^{-1}$ usando micélio lavado com água e acetona e centrifugado. Anteriormente, Colin et al.,${ }^{34}$ trabalhando com a mesma linhagem de $A$. niger, mas cultivada em meio suplementado com óleo de oliva e $\mathrm{Fe}^{+3}$, relataram atividade hidrolítica de aproximadamente $1.800 \mathrm{mU} \mathrm{g}^{-1}$ utilizando micélio úmido (lavado e centrifugado). Sun et al. ${ }^{35}$ purificaram a lipase ligada ao micélio de Rizhopus chinensis. No inicio de seu trabalho, eles mensuraram a atividade de lipase na biomassa bruta em $4.8 \mathrm{U} \mathrm{g}^{-1}$ (equivalente a $4.800 \mathrm{mU} \mathrm{g}^{-1}$ ).

Dentre os trabalhos que localizamos, apenas dois relataram atividades maiores dos que as obtidas em nosso estudo. De Castro et al., trabalhando com o micélio liofilizado de A. westerdijkiae, relataram o excepcional valor $40.000 \mathrm{U} \mathrm{g}^{-1}$ (equivalente a 40.000 .000 de $\mathrm{mU}$ $\left.\mathrm{g}^{-1}\right) .{ }^{25}$ Yadav et al., utilizando micelio ressuspendido em tampão de Yarrowia lipolytica (linhagem NCIM 3639), obtiveram $101 \mathrm{U} \mathrm{g}^{-1}$ (o equivalente a $101.000 \mathrm{mU} \mathrm{g}^{-1}$ ) de atividade. ${ }^{36}$

\section{Avaliação da atividade sintética}

Os tempos médios de retenção para o palmitato de metila (padrão interno), palmitato de etila (produto da transesterificação) e palmitato de p-nitrofenila (reagente limitante) foram, na ordem: 7.98, $8.94 \mathrm{e}$ 15.22 minutos (Figura 3)

A Figura 4 exibe os percentuais da atividade sintética relativa de cada isolado fúngico, calculados a partir da atividade específica

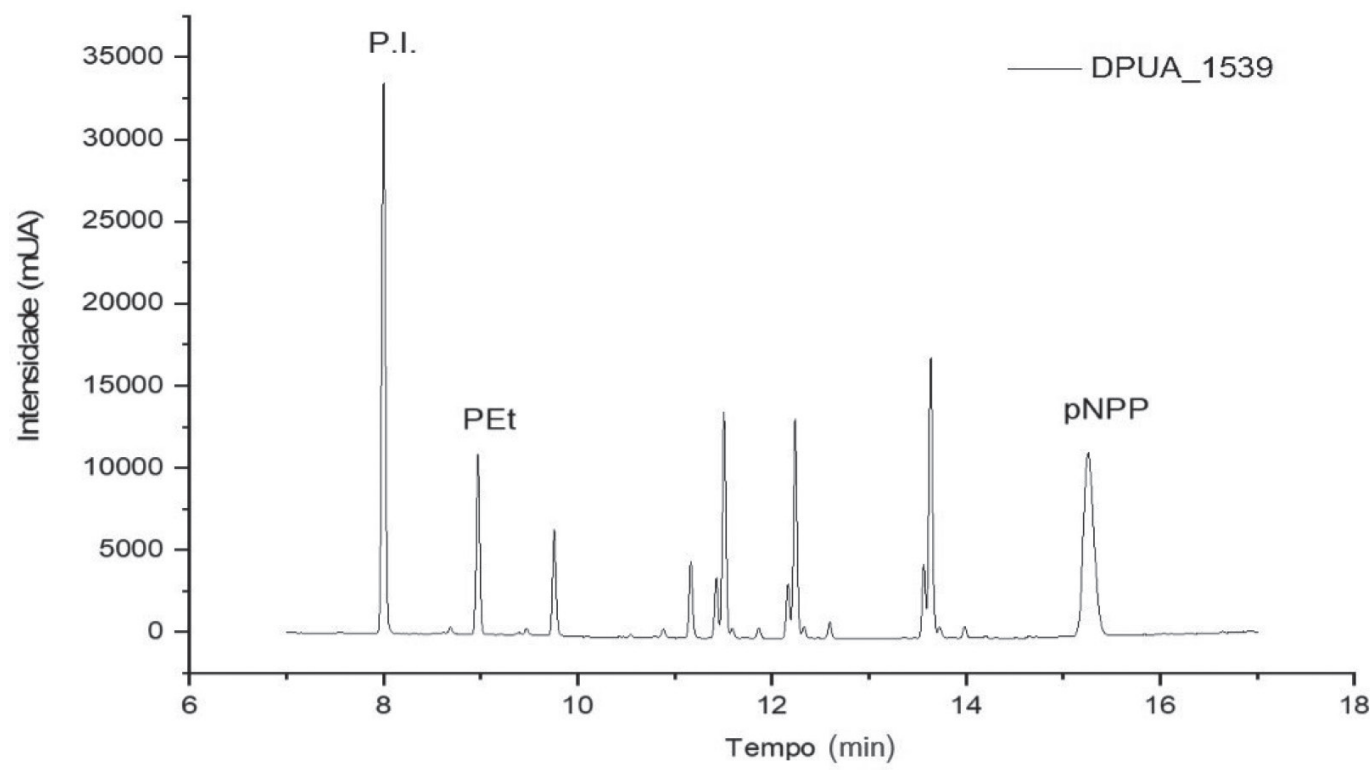

Figura 3. Cromatograma da transesterificação biocatalisada pelo isolado DPUA_1539, indicando os picos correspondentes ao padrão interno palmitato de metila (PI), ao produto (PEt) e ao reagente limitante ( $p N P P$ )

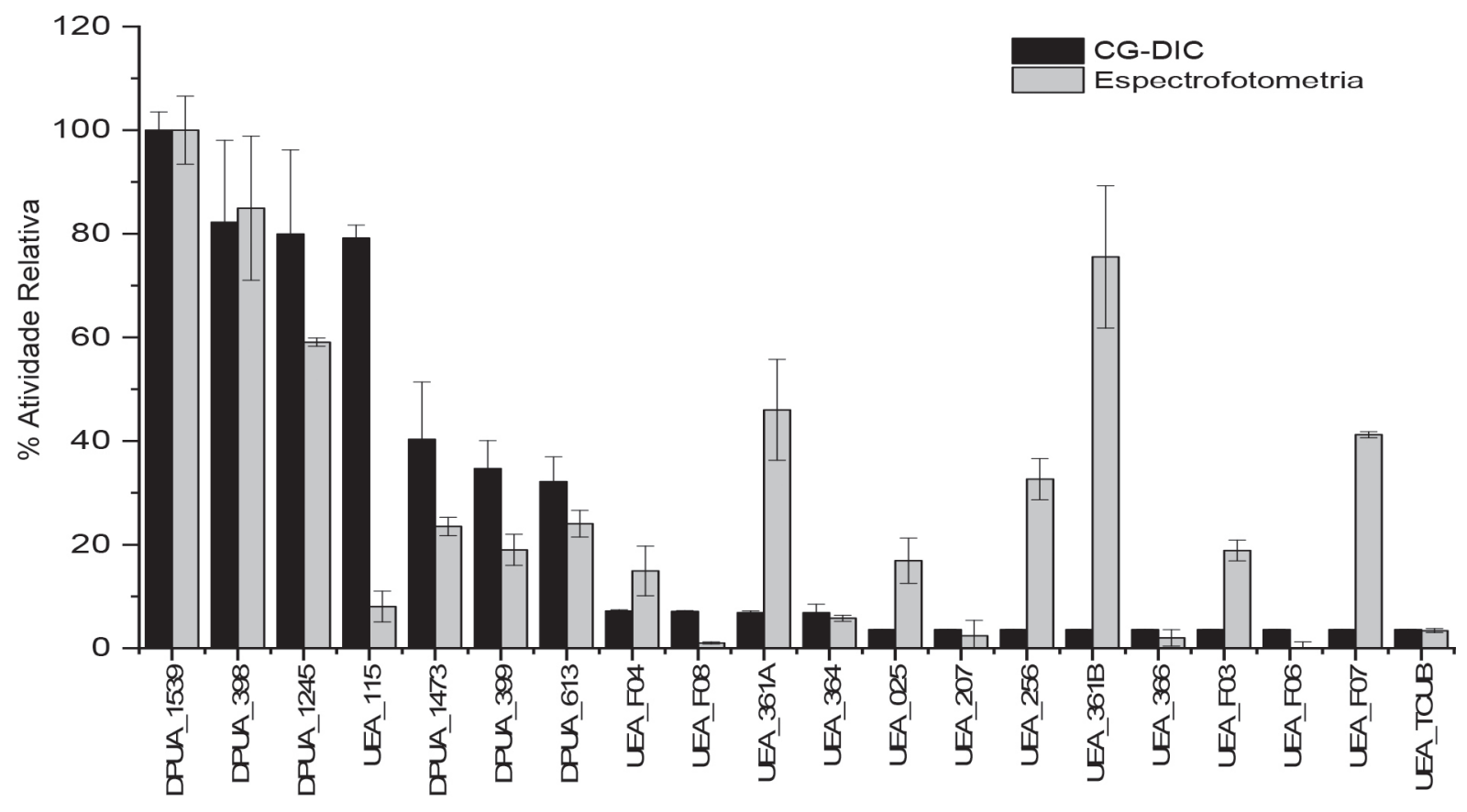

Isolados Fúngicos

Figura 4. Atividade sintética relativa do isolados fúngicos, calculada a partir da atividade específica determinada por CG-DIC e por espectrofotometria 
determinada por CG-DIC (detecção do PEt) e por espectrofotometria (detecção do pNP por absorbância a $410 \mathrm{~nm}$ ).

O isolado DPUA_1539 A. flavo-furcatis apresentou os valores absolutos mais altos de atividade específica na formação de ambos os produtos, a saber, $668,5 \pm 23,5 \mathrm{mU}$ g- ${ }^{1}$ para a formação PEt e $600,5 \pm 39,4 \mathrm{mU} \mathrm{g}-^{1}$ para o pNP. Os percentuais de conversão foram respectivamente $10 \%$ e $9 \%$. Por essa razão, este isolado foi escolhido para ser o padrão de referência, equivalente a $100 \%$ de atividade relativa em ambas as metodologias.

Verificou-se que, para 14 isolados, a diferença entre as atividades relativas foi inferior a $21 \%$. Dentre estes isolados, os cinco com menores percentuais calculados segundo a espectrofotometria (menos que 5\%) também apresentaram baixos percentuais de acordo com cromatografia gasosa (menos que 10\%). Esses resultados indicam uma razoável concordância entre as duas metodologias de determinação da atividade enzimática. Uma exceção notável foi o isolado UEA_115, com apenas $8 \%$ de atividade de acordo com a espectrofotometria, mas $79,2 \%$ de atividade segundo a cromatografia gasosa. Por outro lado, os isolados UEA_361a, UEA_361b, UEA_256 e UEA_F07 apresentaram percentuais expressivos segundo a espectrofotometria (acima de 30\%) e percentuais muitos baixos de acordo com a cromatografia gasosa (menos de 4\%).

A transesterificação é a reação central na produção de biodiesel - um dos tópicos de maior relevância para a biocatálise nestas primeiras décadas do século XXI. Ensaios de transesterificação biocatalisada de triacilgliceróis para a obtenção de biodiesel tipicamente duram muitas horas ou mesmo dias. Assim, na prospecção de novas enzimas microbianas para utilização na produção de biodiesel, um ensaio de baixo custo que permita verificar de forma rápida e precisa a capacidade de transesterificação é de grande utilidade. O ensaio de transesterificação do pNPP com etanol, proposto por Teng e $\mathrm{Xu},{ }^{26}$ tem como pontos altos o baixo custo e a rapidez na verificação do resultado. Entretanto, a comparação dos resultados obtidos em nosso trabalho, levando em conta a maior sensibilidade e robustez da quantificação de produtos via CG-DIC, sugere que o ensaio espectrofotométrico de Teng e Xu é suscetível a resultados falsos positivos. A literatura indica que p-nitrofenol ésteres podem eventualmente sofrer hidrólise não-enzimática. ${ }^{37}$ No caso de enzimas não-purificadas, é preciso levar em conta a possibilidade de que compostos provenientes do meio de cultivo ou da matriz celular possam interferir na leitura da absorbância. Mesmo o processo de delipidação empregado neste trabalho pode não remover por completo estes interferentes. Ainda assim, a relativa concordância entre as metodologias sugere que o ensaio espectrofotométrico pode ser empregado como triagem preliminar, qualitativa, visando eliminar da seleção as linhagens menos promissoras.

Os resultados mostrados na Figura 4 também permitem verificar que as linhagens de Aspergillus tiveram seis dos sete resultados mais altos de atividade sintética avaliada pela formação de PEt. De fato, diversos estudos relacionados à síntese de ésteres e ao biodiesel empregaram lipases ligadas ao micélio deste gênero de fungo..$^{25,33,34,38,39}$ Romero et al.$^{39}$ e Colin et al ${ }^{34}$ avaliaram a atividade sintética das lipases ligadas ao micélio de A. niger MYA 135 pela transesterificação entre pNPP e etanol, mensurada pela liberação do pNP detectada a $405 \mathrm{~nm}$. Usando micélio lavado superficialmente com acetona e centrifugado, Romero et al. obtiveram como melhor resultado 69,4 $\pm 9,4 \mathrm{mU} \mathrm{g}^{-1}$. Empregando micélio que fora apenas centrifugado, Colin et al. relataram com melhor atividade o valor de $59,3 \pm 3,8 \mathrm{mU} \mathrm{g}^{-1}$. Como comparação, em nosso estudo a atividade sintética da biomassa delipidada de A. niger DPUA_398 deteminada pelo método espectrofotométrico foi expressivamente superior, sendo de $510,1 \pm 83,6 \mathrm{mU} \mathrm{g}^{-1}$. A cromatografia gasosa apresentou um valor de atividade semelhante para este isolado $\left(549,7 \pm 105,8 \mathrm{mU} \mathrm{g}^{-1}\right)$.

\section{Avaliação da enantiosseletividade}

Os isolados DPUA_1245,UEA_364 e UEA_366 não foram testados nesta etapa por não terem produzido massa micelial suficiente para utilização na reações. Assim, verificou-se a atividade enantiosseletiva de lipases de dezessete isolados fúngicos através da resolução do ibuprofeno racêmico pela esterificação com 1-propanol em isooctano. Dois destes isolados apresentaram atividade enantioseletiva. A Tabela 1 apresenta os melhores resultados obtidos com estes fungos.

Tabela 1. Atividade enantiosseletiva de lipase na esterficação do $(R, S)$ ibuprofeno

\begin{tabular}{lcccc}
\hline \begin{tabular}{l} 
Isolado fúngico* \\
\hline $\begin{array}{l}\text { DPUA_1539 } \\
\text { (A. flavo-furcatis) }\end{array}$
\end{tabular} & $E$ & $\% \mathrm{c}$ & $\%$ ee & $\begin{array}{c}\text { Tempo de } \\
\text { reação (h) }\end{array}$ \\
UEA_115 & 3,58 & $11 \pm 3$ & $7 \pm 0$ & 144 \\
\hline
\end{tabular}

*As lipases de ambos os isolados demonstraram enantiopreferência pelo (R)-ibuprofeno.

A resolução cinética enzimática utilizando lipases envolve discriminar entre os enantiômeros e melhorar a taxa de hidrólise ou esterificação de um deles. ${ }^{12} \mathrm{O}$ paramêtro adimensional $E$, denominado razão enantiomérica, descreve a dependência da conversão (c) e do excesso enantiomérico do substrato $\left(\mathrm{ee}_{\mathrm{s}}\right)$, permitindo avaliar a seletividade da resolução do racemato. Embora a qualidade de uma resolução cinética seja caracterizada pelo excesso enantiomérico, um elevado valor da razão enantiomérica é essencial para o sucesso da resolução. Um valor de $E$ alto assegura não apenas um excesso enantiomérico elevado, mas também um rendimento proporcionalmente alto. Um valor de $E$ abaixo de 10 para qualquer biotransformação evidencia inviabilidade prática como processo enantiosseletivo. Por outro lado, valores de $E$ entre 10 e 30 indicam um processo promissor e, acima de 30 , um processo excelente. ${ }^{29,40}$

Na literatura, a hidrólise enantiosseletiva de $(R, S)$-ésteres de ibuprofeno por lipases tem sido empregada em vários trabalhos como rota enzimática para a obtenção do $S$ enantiômero. Alguns destes trabalhos relatam elevados valores de $E .{ }^{41-44}$ Entretanto, para obtenção da forma $(S)$ do fármaco por esta rota, são necessárias duas etapas prévias: (1) a esterificação do ibuprofeno racêmico por meio de síntese química convencional e (2) a extração dos ésteres de ibuprofeno formados na primeira etapa. Por outro lado, a esterificação do $(R, S)$-ibuprofeno por uma lipase com elevada preferência pelo R-enantiômero é uma rota alternativa que possibilitaria o isolamento do $(S)$-ibuprofeno em um número menor de etapas. ${ }^{45}$

Avaliando os resultados deste trabalho pelo critério do valor de E, verifica-se que o isolado DPUA_1539 A. flavo-furcatis mostrou-se bastante promissor como fonte de lipase para resolução do ibuprofeno racêmico via esterificação enantiosseletiva $(E=24,15)$. Além do valor expressivo do parâmetro $E$, a preferência pelo $R$ enantiômero demonstrada pela lipase desse isolado é, conforme o exposto acima, uma característica altamente desejável na resolução do $(R, S)$-ibuprofeno por esterificação (Figura 5) .

Mohammadi et al., ${ }^{46}$ utilizando a lipase comercial de Rhizomucor miehei imobilizada em nanopartículas de sílica para biocatalisar a esterificação do ibuprofeno racêmico, obtiveram $E=33,9$ com $25,8 \%$ de conversão após 10 h de reação. Entretanto, a lipase imobilizada mostrou preferência pelo enantiômero $\mathrm{S}$, tornando necessária uma etapa adicional de hidrólise do éster de $(S)$-ibuprofeno para obtenção da forma enantiopura do fármaco.

Uma extensa revisão sobre a resolução cinética enzimática do ibuprofeno foi preparada por José, Toledo e Briand. ${ }^{12}$ Estas autoras 


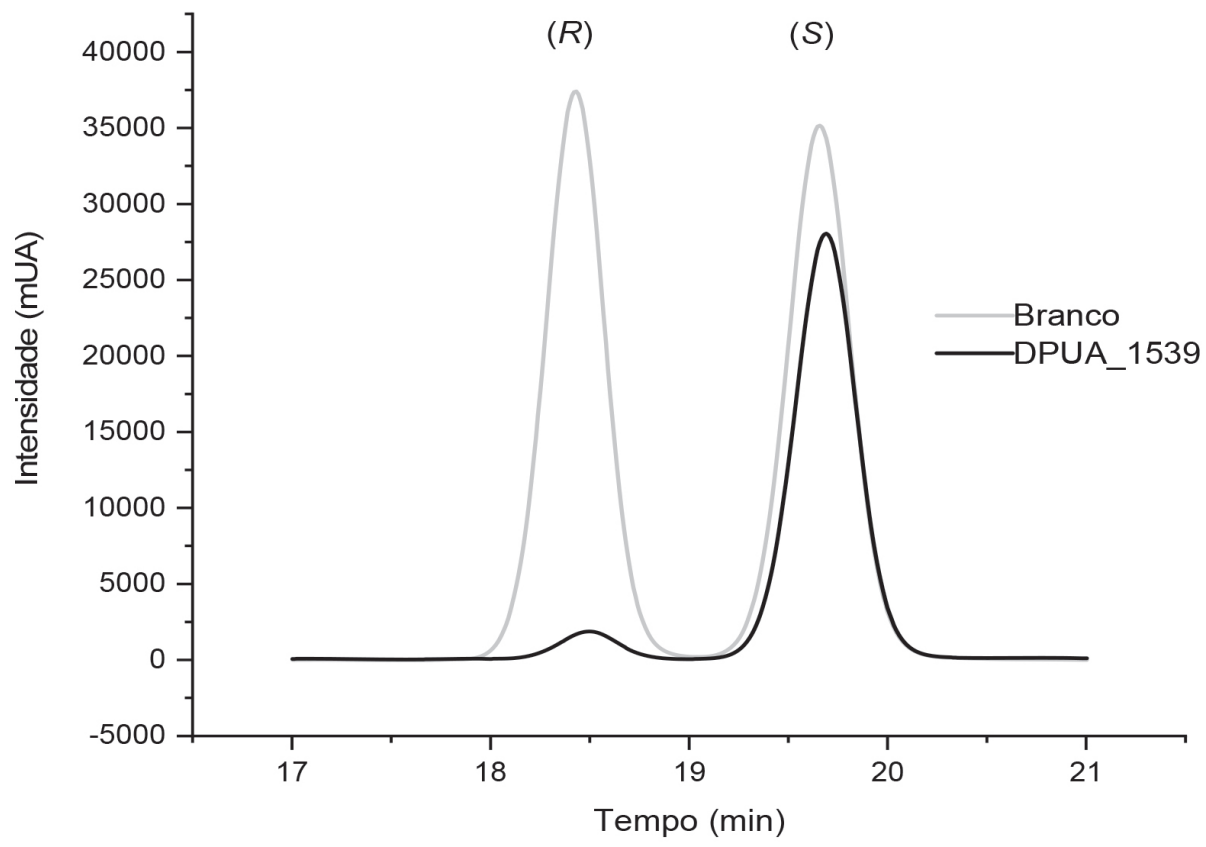

Figura 5. Enantiopreferência pelo (R)-enantiômero na reação de esterificação do ibuprofeno racêmico biocatalisada pelo isolado DPUA_1539 A. flavo-furcatis, após $96 h$ de reação

alistaram 26 artigos publicados nos vinte anos anteriores sobre este tema, detalhando os biocatalisadores utilizados (enzimas purificadas ou nativas, imobilizadas ou não), o tipo de solventes e reagentes empregados e os principais resultados obtidos. Apenas três destes trabalhos ${ }^{27,47,48}$ investigaram o uso lipases do gênero Aspergillus como biocatalisadores, e o fizeram utilizando somente as enzimas extracelulares precipitadas e liofilizadas. Dos trabalhos sobre resolução enzimática do ibuprofeno aos quais tivemos acesso, apenas Romano et al. ${ }^{49}$ testaram a biomassa micelial de um Aspergillus (A. oryzae) como fonte de lipases para resolução cinética do ibuprofeno, e com um resultado excelente ( $\mathrm{E}=61$ após $24 \mathrm{~h}$ de reação). Os resultados obtidos por Romano et al., bem como os resultados obtidos em nosso trabalho, sugerem que a utilização de lipases ligadas a biomassa de espécies de Aspergillus para resolução do ibuprofeno é um campo de investigação promissor e que merece receber mais atenção.

\section{Identificação molecular}

A linhagem UEA_115, por apresentar bons resultados de atividade sintética e atividade enantiosseletiva, teve sua identificação refinada por métodos moleculares. A abordagem molecular para essa linhagem gerou uma sequência de 1129 bp contendo as regiões polimórficas ITS1, ITS2 e D1/D2 com a margem de erro média por base de $0,1 \%$ (PHRED Quality Score $=30$ ). A comparação com o banco de dados revelou que essa linhagem pertence à família Botryosphaeriaceae, com identidade de $99 \%$ com a espécie Lasiodiplodia pseudotheobromae (códigos de acesso GenBank FN645639.1).

\section{CONCLUSÃO}

A biomassa de isolados fúngicos amazônicos avaliada neste estudo apresentou atividade de lipase hidrolítica, sintética e enantiosseletiva com potencial para aplicação em diversos campos de biocatálise. Para a maioria dos isolados testados, a biomassa delipidada e cultivada em meio com óleo de oliva mostrou-se o tratamento com resultados mais altos de atividade de hidrólise, quando comparados aos resultados obtidos com a biomassa não-delipidada ou cultivada em meio sem indutor.
A biomassa delipidada das seis linhagens de Aspergillus e da linhagem UEA_115 apresentou elevada atividade de síntese por meio da reação de esterificação do palmitato de etila em meio orgânico, confirmada por duas metodologias diferentes (cromatografia gasosa e espectrofotometria). O isolado DPUA_1539 A. flavo-furcatis apresentou a atividade sintética mais alta entre todos os isolados $(668,5 \pm 23,5$ $\mathrm{mU} \mathrm{g}^{-1}$, de acordo com a cromatografia gasosa). Esses resultados encorajam investigações adicionais destes fungos como potenciais fornecedores de lipase para a produção de biodiesel.

Os ensaios de atividade enantiosseletiva indicaram que o isolado UEA_115 $(E=3,58)$ e, em especial, o isolado DPUA_1539 A. flavo-furcatis $(E=24,15)$, possuem a capacidade de discriminar os enantiômeros do ibuprofeno racêmico pela síntese de éster, preferencialmente com o $(R)$-enantiômero. Vislumbra-se, desse modo, a perspectiva de utilização dessas linhagens como biocatalisadores na produção de uma formulação enantiopura do fármaco.

\section{AGRADECIMENTOS}

À FAPEAM, pelo suporte financeiro na forma de concessão de uma bolsa de doutoramento ao primeiro autor (Edital nº 003/2015).

Aos pesquisadores M. F. S. Texeira (DPUA-UFAM), R. E. L. Procópio (MBT-UEA), A. A. Damasceno (UEA), A. Q. L. Souza (FCA-UFAM) e C. Sales-Campos (INPA) por contribuirem com linhagens fúngicas e/ou reagentes, além de outros insumos indispensáveis para a realização deste trabalho.

Aos colaboradores J. N. de Souza Neto e F. M. A. da Silva (CAMUFAM), E. Bacelar (MBT-UEA) e C. S. de Morais (FUCAPI) pelo apoio na análise instrumental.

\section{REFERÊNCIAS}

1. Cortez, D. V.; De Castro, H. F.; Andrade, G. S. S.; Quim. Nova 2017, 40, 85.

2. Guerrand, D.; Oilseeds Fats Crop. Lipids 2017, $24,1$.

3. Salihu, A.; Alam, M. Z.; Process Biochem. 2015, 50, 86.

4. Daiha, K. de G.; Angeli, R.; de Oliveira, S. D.; Almeida, R. V.; PLoS One 2015, 10, 1. 
5. Kourist, R.; Hollmann, F.; Nguyen, G.; JSM Biotechnol. Biomed. Eng. 2014, 2,1 .

6. Hama, S.; Noda, H.; Kondo, A.; Curr. Opin. Biotechnol. 2018, $50,57$.

7. Imanparast, S.; Hamedi, J.; Faramarzi, M. A.; Food Chem. 2018, 245 , 934.

8. Ciudad, G.; Reyes, I.; Azócar, L.; Briones, R.; Jorquera, M.; Wick, L. Y.; Navia, R.; Nat. Biotechnol. 2011, 28, 375.

9. Zago, E.; Botton, V.; Alberton, D.; Yamamoto, C. I.; Co, C.; Mitchell, D. A.; Krieger, N.; Energy Fuels 2014, 28, 5197.

10. Hudlicky, T.; Reed, J. W.; Chem. Soc. Rev. 2009, 38, 3117.

11. Yuan, X.; Wang, L.; Liu, G.; Dai, G.; Tang, K.; Chirality 2019, 31, 445.

12. José, C.; Toledo, M. V.; Briand, L. E.; Crit. Rev. Biotechnol. 2015, 36, 1.

13. Ghanem, A.; Aboul-Enein, M. N.; El-Azzouny, A.; El-Behairy, M. F.; J. Chromatogr. A 2010, 1217, 1063.

14. Zheng, J.; Fu, X.; Ying, X.; Zhang, Y.; Wang, Z.; Anal. Biochem. 2014, $452,13$.

15. Zhang, J. H.; Lin, Y.; Sun, Y. F.; Ye, Y. R.; Zheng, S. P.; Han, S. Y.; Enzyme Microb. Technol. 2012, 50, 325.

16. Pöhnlein, M.; Finkbeiner, T.; Syldatk, C.; Hausmann, R.; Biotechnol. Lett. 2015, 37, 705 .

17. Geoffry, K.; Achur, R. N.; Biocatal. Agric. Biotechnol. 2018, 14, 241.

18. Mehta, A.; Bodh, U.; Gupta, R.; J. Biotech Res. 2017, 8, 58.

19. Loo, J. L.; Khoramnia, A.; Lai, O. M.; Long, K.; Ghazali, H. M.; Molecules 2014, 19, 8556.

20. Zanotto, S. P.; Romano, I. P.; Lisboa, L. U. S.; Duvoisin, S. J.; Martins, M. K.; Lima, F. A.; Silva, S. F.; Albuquerque, P. M.; J. Braz. Chem. Soc. 2009, 20, 1046.

21. Zhang, Z.; Schwartz, S.; Wagner, L.; Miller, W.; J. Comput. Biol. 2000, 7, 203.

22. Sun, S. Y.; Xu, Y.; Bioresour. Technol. 2009, 100, 1336.

23. Torres, M.; Dolcet, M. M.; Sala, N.; Canela, R.; J. Agric. Food Chem. 2003, 51, 3328 .

24. Fernandes, M. L. M.; Saad, E. B.; Meira, J. A.; Ramos, L. P.; Mitchell, D. A.; Krieger, N.; J. Mol. Catal. B: Enzym. 2007, 44, 8.

25. de Castro, F. F.; Pinheiro, A. B. P.; Nassur, C. B.; Barbosa-Tessmann, I. P.; Biocatal. Agric. Biotechnol. 2017, 10, 321.

26. Teng, Y.; Xu, Y.; Anal. Biochem. 2007, 363, 297.

27. Carvalho, P. D. O.; Contesini, F. J.; Bizaco, R.; Calafatti, S. A.; Macedo, G. A.; J. Ind. Microbiol. Biotechnol. 2006, 33, 713.

28. Chen, C. S.; Fujimoto, Y.; Girdaukas, G.; Sih, C. J.; J. Am. Chem. Soc. 1982, 104, 7294.
29. Faber, K.; Kroutil, W.; Selectivity 2012, 1, 5.

30. Faber, K.; Biotransformations in Organic Chemistry, $6^{\text {th }}$ ed., SpringerVerlag: Berlin, 2011.

31. Fell, J. W.; Mol. Mar. Biol. Biotechnol. 1993, 2, 174.

32. Altschul, S. F.; Gish, W.; Miller, W.; Myers, E. W.; Lipman, D. J.; J. Mol. Biol 1990, 215, 403.

33. Regner, E. L.; Natalia, H.; Domingo, M.; María, L.; Biomass Bioenergy 2019, 120, 59.

34. Colin, V. L.; Baigorí, M. D.; Pera, L. M.; J. Basic Microbiol. 2011, 51, 236.

35. Sun, S. Y.; Xu, Y.; Wang, D.; Bioresour. Technol. 2009, 100, 2607.

36. Yadav, K. N. S.; Adsul, M. G.; Bastawde, K. B.; Jadhav, D. D.; Thulasiram, H. V.; Gokhale, D. V.; Bioresour. Technol. 2011, 102, 10663.

37. Stoytcheva, M.; Stoytcheva, M.; Montero, G.; Zlatev, R.; León, J. Á.; Gochev, V.; Curr. Anal. Chem. 2012, 8, 400.

38. Reinehr, C. O.; Treichel, H.; Revista Ciências Exatas e Naturais 2016 , $18,97$.

39. Romero, C. M.; Pera, L. M.; Loto, F. V.; Costas, L.; Baigorí, M. D.; Catal. Lett. 2013, 143, 469.

40. Costa, V. E. U.; De Amorim, H. L. N.; Quim. Nova 1999, 22, 863.

41. Gandomkar, S.; Habibi, Z.; Mohammadi, M.; Yousefi, M.; Salimi, S.; Biocatal. Agric. Biotechnol. 2015, 4, 550.

42. Yousefi, M.; Mohammadi, M.; Habibi, Z.; J. Mol. Catal. B: Enzym. 2014, 4, 550.

43. Gonawan, F. N.; Yon, L. S.; Kamaruddin, A. H.; Uzir, M. H.; J. Chem. Technol. Biotechnol. 2013, 88, 672.

44. Habibi, Z.; Mohammadi, M.; Yousefi, M.; Process Biochem. 2013, 48, 669.

45. Carvalho, P. D. O.; Calafatti, S. A.; Marassi, M.; Da Silva, D. M.; Contesini, F. J.; Bizaco, R.; Macedo, G. A.; Quim. Nova 2005, 28, 614.

46. Mohammadi, M.; Habibi, Z.; Gandomkar, S.; Youse, M.; Int. J. Biol. Macromol. 2018, 117, 523.

47. Carvalho, P. D. O.; Contesini, F. J.; Ikegaki, M.; Braz. J. Microbiol. 2006, 37, 329.

48. Contesini, F. J.; de Oliveira Carvalho, P.; Tetrahedron: Asymmetry 2006 , 17, 2069

49. Romano, A.; Gandolfi, R.; Molinari, F.; Converti, A.; Zilli, M.; Del Borghi, M.; Enzyme Microb. Technol. 2005, 36, 432. 